\title{
PENGARUH PIJAT PERINEUM PADA KEHAMILAN TRIMESTER III TERHADAP ROBEKAN PERINEUM PRIMIGRAVIDA DI PUSKESMAS JAGIR SURABAYA
}

\author{
THE EFFECT OF PERINEAL MASSAGE DURING THE THIRD \\ TRIMESTER PREGNANCY ON THE PREVENTION OF PRIMIGRAVIDA \\ PERINEAL RUPTURE \\ AT COMMUNITY HEALTH CENTER IN JAGIR SURABAYA.
}

\author{
${ }^{1}$ Fritria Dwi Anggraini, SST., M.Kes, ${ }^{2}$ Yasi Anggasari, SST., M.Kes \\ (UNUSA, FKK, Prodi D III Kebidanan - Jl. Smea 57 Surabaya) \\ Email : fitria@unusa.ac.id dan yasi@unusa.ac.id
}

\begin{abstract}
Abstrak: Robekan perineum bisa terjadi secara spontan (ruptur) atau disengaja (episiotomi). Upaya yang untuk melenturkan perineum antara lain pijat perineum yang belum dilakukan di puskesmas jagir. Tujuan penelitian ini adalah mengetahui pengaruh pijat perineum pada kehamilan trimester III terhadap robekan perineum primigravida di Wilayah Kerja Puskesmas Jagir Surabaya. Desain penelitian Quasi-eksperimental dengan pendekatan posttest only group design. Populasinya adalah semua ibu hamil fisiologis primigravida trimester III yang bersalin di Puskesmas Jagir dengan sampel 20 responden yaitu 10 responden kelompok perlakuan dan 10 responden kelompok kontrol. Variabel independent yaitu pijat perineum dan variabel dependent yaitu robekan perineum. Pengumpulan data menggunakan SOP dan lembar partograf/ rekamedis. Data dianalisis dengan uji Mann Whintney dengan $\alpha=0,05$. Hasil penelitian pada pengaruh menunjukkan hampir semuanya responden $(80,0 \%)$ tidak terjadi robekan perineum pada kelompok perlakuan dan sebagian besar responden $(60,0 \%)$ terjadi robekan perineum pada kelompok kontrol. Hasil uji statistik dengan menggunakan Mann Whitney didapatkan hasil $p=0,001<\alpha=0,05$ maka Ho ditolak artinya ada pengaruh pijat perineum pada kehamilan trimester III terhadap robekan perineum primigravida di Wilayah Kerja Puskesmas Jagir Surabaya. Responden yang dilakukan pijat perineum hampir semuanya tidak terjadi robekan maka dari itu pijat perineum bisa melenturkan perineum agar tidak terjadi robekan perineum. Oleh karena itu diharapkan bagi petugas kesehatan untuk lebih menganjurkan ibu untuk melakukan pijat perineum dalam mempersiapkan proses persalinan.
\end{abstract}

Kata kunci: Pijat perineum, robekan perineum.

\begin{abstract}
Perineal rupture may occur spontaneously (ruptured) or deliberately (episiotomy). An attempt to Flex the perineum perineum massage among others who haven't performed in clinics jagir. The objective of this research was to find out the effect of perineal massage during the third trimester of pregnancy on the prevention of primigravida perineal rupture in Community Health Center in Jagir-Surabaya. The research design was Quasi-experimental with post-test only group model. The population was all pregnant mothers - of primigravida physiologic category of the third trimester - who delivered at Community Health Center in Jagir Surabaya with its sample of 20 respondents, that is, 10 respondents of the treatment group and 10 respondents of the control group. The independent variable was perineal massage, and the dependent variable was perineal rupture. The data collection was carried out using SOP and partographic sheet / medical record. The data were analyzed by Mann Whintney test with $\alpha=0.05$. The Result of the research showed that almost all respondents $(80.0 \%)$ did not experience perineal rupture in treatmen group and most $(60.0 \%)$ of those respondents experiencing torn perineum were suffering from perineal tear in control group. The result of the statistic test using Mann Whitney showed $p=0.001<\alpha=0.05$, then Ho was refused, meaning there was effect of perineal massage during the third trimester pregnancy on the prevention of primigravida perineal rupture at Community Health Center in Jagir surabaya. Respondents who do the massage the perineum almost everything does happen rips therefore massage the perineum can Flex the perineum so as not happening rips the perineum. Therefore it was suggested that the health workers encourage the pregnant mothers to have perineal massage treatment during theperiod of maternity preparation.
\end{abstract}

Keywords: Perineal massage, perineal rupture. 


\section{PENDAHULUAN}

Persalinan merupakan hal fisiologis yang dialami setiap wanita, dan setiap wanita ingin menjalani proses persalinan dengan normal. Proses persalinan normal diawali dengan terjadinya kontraksi uterus yang teratur, diikuti dengan pembukaan serviks, dan sampai dikeluarkannya hasil konsepsi meliputi janin, palsenta, ketuban dan cairan ketuban dari uterus melalui vagina, dengan usaha dan kekuatan ibu sendiri.

Persalinan adalah sebuah hal yang fisiologis, akan tetapi pada proses persalinan juga bisa timbul penyulit. Penyulit pada proses persalinan ada berbagai macam, salah satunya pada jalan lahir yaitu pada jalan lahir yaitu robekan perineum. Robekan perineum bisa terjadi secara spontan (ruptur) atau disengaja (episiotomi). Pada umumnya robekan perineum dapat disembuhkan tetapi hal ini dapat mengganggu kenyamanan ibu pada masa nifas. Tidak sedikit ibu yang mengalami luka perineum, dimana luka perineum itu bisa menyebabkan terjadinya infeksi jika tidak ditangani dengan tepat. Infeksi itu sendiri merupakan salah satu kasus (penyakit) yang paling banyak terjadi pada masa nifas. Infeksi bisa disebabkan karena infeksi luka perineum, servik, uteri, endometritis, septicemia, piemia, peritonitis, dan selulitis pelvik. Menurut data dari Dinas Kesehatan Profinsi Jawa Timur angka penyebab kematian ibu dengan infeksi juga cukup tinggi pada tahun 2011 sebanyak 6,06\%, tahun 2012 sebanyak 4,98\%, tahun 2013 sebanyak 6,07\%, tahun 2014 sebanyak 6,17\% (Profil Kes. Provinsi Jatim, 2014). sebanyak 117 orang $(33,33 \%)$.

Robekan perineum umumnya terjadi pada ibu primigravida karena jalan lahir belum pernah dilalui bayi sama sekali dan otot masih kaku, tetapi pada ibu multigravida tidak menutup kemungkinan juga bisa mengalami robekan perineum. Ibu yang sudah melahirkan seharusnya perineum bisa menjadi elastis, namun kenyataannya masih ditemui ibu multigravida saat persalinan tetap mengalami robekan perineum. Hal ini menunjukkan bahwa multigravida saja tidak cukup meminimalkan robekan perineum, dan sudah pernah dilalui pun tidak menjamin perineum mejadi elastis. Berdasarkan hasil data prasurvey di Puskesmas Jagir didapatkan jumlah persalinan normal pada bulan Mei-September sebanyak 267 orang, dari jumlah tersebut dapat dikelompokkan antara persalinan primigravida sebanyak 55 orang dan multigravida sebanyak 183 orang. Pada persalinan primigravida didapatkan angka kejadian rupture perineum 54 orang (98\%), sedangkan persalinan primigravida yang tidak mengalami rupture sebanyak 1 orang (2\%). Dan pada persalinan multigravida didapatkan angka kejadian rupture sebanyak 156 orang (85\%), sedangkan persalinan multigravida yang tidak mengalami rupture perineum sebanyak 27 orang $(15 \%)$. Hal ini menunjukkan bahwa tidak hanya primigravida yang angka kejadian robekan masih tinggi, tetapi multigravida juga angka kejadian robekan masih tinggi.

Robekan perineum sebenarnya dapat dicegah atau tidak perlu terjadi, jika perineum elastis, atau ibu bisa mengejan dengan baik oleh karena itu banyak cara untuk mencegah terjadinya robekan perineum. Upaya-upaya untuk mencegah robekan perineum telah dilakukan antara lain senam kegel dan senam hamil.

Selain senam hami dan senam kegel upaya untuk mencegah robekan bisa dengan teknik pijat perineum, tetapi tidak banyak orang yang mengetahui pijat ini bisa mencegah terjadinya robekan perineum. Padahal pijat ini sangat mudah dilakukan dan dapat dilakukan dengan sendiri tanpa membutuhkan waktu yang lama, bisa juga dilakukan setiap hari dan tidak membutukan biaya yang mahal.

Pijat perineum adalah teknik memijat perineum yang dilakukan saat hamil atau 2 minggu sebelum persalinan yang bermanfaat untuk melembutkan jaringan ikat, melancarkan peredaran darah, relaksasi. Tindakan ini akan mengurangi terjadinya rupture perineum, episiotomi dan nyeri karena jahitan episiotomy (Indivara, 2009). Maka peneliti tertarik ingin melakukan upaya pencegahan robekan perineum dengan pijat perineum, agar ibu primigravida merasa nyaman saat nifas dan mengurangi angka kejadian infeksi pada masa nifas.

\section{METODE PENELITIAN}

Jenis penelitian yang digunakan adalah Quasieksperimental dengan pendekatan posttest only group design. Penelitian ini menentukan dari suatu perlakuan (intervensi) pada kelompok eksperimen dengan cara membandingkan dengan kelompok kontrol. Pada rancangan ini, kelompok eksperimental diberi perlakuan sedangkan 
kelompok kontrol tidak. Dalam penelitihan ini ibu primigravida trimester III diberikan perlakuan pijat perineum dan sebagian ibu primigravida tidak diberikan perlakuan karena sebagai kelompok pembanding. Pemberian perlakuan pijat perineum pada ibu primigravida trimester III dilakukan sebelum persalinan pada usia kehamilan 9 bulan atau 36 minggu, dilakukan pemijatan setiap hari. Sedangkan untuk mengetahui robekan perineum setelah ibu melahirkan atau pada saat ibu melahirkan.

Pengambilan sampel yang dilakukan dalam penelitian ini menggunakan Nonprobability dengan teknik total sampling yaitu semua populasi dijadikan sampel. Instrument penelitian ini, variabel independen pelaksanaan pijat perineum menggunakan SOP pijat perineum dan mengukur variabel dependen robekan perineum menggunakan skala pengukuran robekan perineum dengan melihat rekam medis atau patograf. uji Mann Whitney dengan tingkat kemaknaan $\alpha=$ 0,05 . Jika hasil uji statistika menunjukkan $\rho<0,05$ maka hipotesis penelitian $\left(\mathrm{H}_{0}\right)$ diterima berarti ada pengaruh. Menggunakan skala pengukuran robekan perineum dengan melihat rekam medis atau patograf. uji Mann Whitney dengan tingkat kemaknaan $\alpha=0,05$. Jika hasil uji statistika menunjukkan $\rho<0,05$ maka hipotesis penelitian $\left(\mathrm{H}_{0}\right)$ diterima berarti ada pengaruh.

\section{HASIL DAN PEMBAHASAN \\ HASIL}

1. Data Umum

a. Karakteristik responden berdasarkan usia

Menurut Prawirohardjo (2012) penggolongan usia dibagi menjadi beberapa katagorik yaitu usia $<20$ tahun, usia 21-35 tahun, usia >35 tahun. Karakteristik responden berdasarkan usia dapat dilihat pada tabel dibawa ini:

1) Kelompok perlakuan

Tabel 5.1 Distribusi frekuensi responden berdasarkan usia pada kelompok perlakuan di Wilayah Kerja Puskesmas Jagir Surabaya 2017

\begin{tabular}{lcc}
\hline Usia (Tahun) & Frekuensi & Persentase (\%) \\
\hline$<20$ & 0 & 0 \\
\hline $21-35$ & 10 & 100 \\
\hline$>35$ & 0 & 0 \\
\hline Jumlah & 10 & 100 \\
\hline
\end{tabular}

Sumber : Data Primer Juni 2017
2) Kelompok kontrol

Tabel 5.2 Distribusi frekuensi responden berdasarkan usia pada kelompok kontrol di Wilayah Kerja Puskesmas Jagir Surabaya 2017

\begin{tabular}{lcc}
\hline $\begin{array}{l}\text { Usia } \\
\text { (Tahun) }\end{array}$ & Frekuensi & $\begin{array}{l}\text { Persentase } \\
(\boldsymbol{\%})\end{array}$ \\
\hline$<20$ & 1 & 10 \\
\hline $21-35$ & 8 & 80 \\
\hline$>35$ & 1 & 10 \\
\hline Jumlah & 10 & 100 \\
\hline
\end{tabular}

Sumber : Data Primer Juni 2017

b. Karakteristik responden berdasarkan usia kehamilan

Menurut Indivara (2009) pemijatan dilakukan pada 2 minggu sebelum persalinan. Dan pengolongan untuk pemijatan pada usia kehamilan <36 minggu dan >36 minggu. Karakteristik responden berdasarkan usia kehamilan dapat dilihat pada tabel dibawah ini:

1) Kelompok perlakuan

Tabel 5.3 Distribusi frekuensi responden berdasarkan usia kehamilan pada kelompok perlakuan di Wilayah Kerja Puskesmas Jagir Surabaya 2017

\begin{tabular}{lcc}
\hline $\begin{array}{l}\text { Usia Kehamilan } \\
\text { (mgg) }\end{array}$ & Frekuensi & $\begin{array}{l}\text { Persentase } \\
(\boldsymbol{\%})\end{array}$ \\
\hline$<36$ minggu & 5 & 50 \\
\hline$>36$ minggu & 5 & 50 \\
\hline Jumlah & 10 & 100 \\
\hline
\end{tabular}

Sumber : Data Primer Juni 2017

2) Kelompok kontrol

Tabel 5.4 Distribusi frekuensi responden berdasarkan usia kehamilan pada kelompok kontrol di Wilayah Kerja Puskesmas Jagir Surabaya 2017

\begin{tabular}{lll}
\hline $\begin{array}{l}\text { Usia } \\
\text { Kehamilan } \\
\text { (mgg) }\end{array}$ & Frekuensi & $\begin{array}{l}\text { Persentase } \\
(\%)\end{array}$ \\
\hline$<36$ minggu & 3 & 30 \\
\hline$>36$ minggu & 7 & 70 \\
\hline Jumlah & 10 & 100 \\
\hline
\end{tabular}

Sumber : Data Primer Juni 2017

c. Karakteristik responden berdasarkan besar bayi

Menurut Menurut Oxorn \& Forte (2010), pengelompokan bayi baru lahir berdasarkan berat badannya adalah sebagai berikut, antara 3500 hingga 4000 gram digolongkan bayi besar, antara 3000 hingga 3500 gram termasuk sedang, dan antara 2500 hingga 3000 gram tergolong kecil. Karakteristik responden berdasarkan besar bayi dapat dilihat pada tabel dibawah ini: 
1) Kelompok perlakuan

Tabel 5.5 Distribusi frekuensi responden berdasarkan besar bayi pada kelompok perlakuan di Wilayah Kerja Puskesmas Jagir Surabaya 2017

\begin{tabular}{lcc}
\hline $\begin{array}{l}\text { Besar bayi } \\
\text { (gram) }\end{array}$ & Frekuensi & Persentase (\%) \\
\hline $2500-3000$ & 3 & 30 \\
\hline $3100-3500$ & 5 & 50 \\
\hline $3600-4000$ & 2 & 20 \\
\hline Jumlah & 10 & 100 \\
\hline
\end{tabular}

Sumber : Data Primer Juni 2017

2) Kelompok kontrol

Tabel 5.6 Distribusi frekuensi responden berdasarkan besar bayi pada kelompok perlakuan di Wilayah Kerja Puskesmas Jagir Surabaya 2017

\begin{tabular}{lcc}
$\begin{array}{l}\text { Besar bayi } \\
\text { (gram) }\end{array}$ & Frekuensi & Persentase (\%) \\
\hline $2500-3000$ & 2 & 20 \\
\hline $3100-3500$ & 4 & 40 \\
\hline $3600-4000$ & 4 & 40 \\
\hline Jumlah & 10 & 100 \\
\hline
\end{tabular}

Sumber : Data Primer Juni 2017

1. Data Khusus

a. Karakteristik responden berdasarkan pijat perineum pada primigravida

Menurut Yasie (2010) pada teknik pemijatan perineum yaitu taruh jari tidak lebih dari $2,54 \mathrm{~cm}$ di bawah mulut vagina (atau maksimum dua buku jari di bawah vagina). Waktu Pemijatan pada usia kehamilan 36 minggu atau dua minggu terakhir dan pemijatan dilakukan setiap hari menjelang hari $\mathrm{H}$ dengan durasi sebagai berikut: Minggu pertama 2 menit, sisa minggu menjelang persalinan 4-5 menit, dan berhenti pada saat ketuban pecah atau persalinan dimulai.

Tabel 5.7 Distribusi frekuensi responden berdasarkan pijat perineum pada kelompok perlakuan yang dilakukan pijat perineum di Wilayah Kerja Puskesmas Jagir Surabaya 2017

\begin{tabular}{|c|c|c|c|c|c|c|c|c|}
\hline \multicolumn{9}{|c|}{ Pijat Perineum } \\
\hline \multicolumn{3}{|c|}{$\begin{array}{c}\text { Frekuensi pijat } \\
\text { perineum }\end{array}$} & \multicolumn{3}{|c|}{$\begin{array}{l}\text { Lama pijat } \\
\text { perineum }\end{array}$} & \multicolumn{3}{|c|}{$\begin{array}{c}\text { Kedalaman } \\
\text { pijat perineum }\end{array}$} \\
\hline & (n) & $(\%)$ & & (n) & $(\%)$ & & (n) & (\%) \\
\hline$<20$ kali & 1 & 10 & $\begin{array}{l}<5 \\
\text { mnt }\end{array}$ & 2 & 20 & $\begin{array}{l}<2, \\
54 \\
\mathrm{~cm}\end{array}$ & 6 & 60 \\
\hline $\begin{array}{l}21-30 \\
\text { kali }\end{array}$ & 2 & 20 & $\begin{array}{l}>5 \\
\mathrm{mnt}\end{array}$ & 8 & 80 & $\begin{array}{l}>2, \\
54 \\
\mathrm{~cm}\end{array}$ & & \\
\hline $\begin{array}{l}31-40 \\
\text { kali }\end{array}$ & 5 & & & & & & & \\
\hline$>41$ kali & 2 & 20 & & & & & & \\
\hline Jumlah & 10 & 100 & & 10 & 100 & & 10 & 100 \\
\hline
\end{tabular}

Sumber : Data Primer, Juni 2017
Berdasarkan tabel 5.7 di dapatkan dari 10 responden dari data pijat perineum meliputi frekuensi pijat perineum menunjukkan setengahnya (50\%) melakukan 31-.40 kali pemijatan perineum, lama pijat perineum menunjukkan hampir semuanya (80\%) melakukan pijat perineum selama $>5$ menit, dan kedalaman pijat perineum menunjukkan sebagian besar $(60 \%)$ melakukan pijat perineum $<2,54 \mathrm{~cm}$ di bawah mulut vagina.

b. Karakteristik responden berdasarkan robekan perineum pada ibu primigravida

1) Kelompok perlakuan

Karakteristik responden berdasarkan robekan perineum setelah dilakukan pijat perineum pada primigravida di Wilayah Kerja Puskesmas Jagir Surabaya dapat dilihat pada tabel sebagai berikut :

Tabel 5.8 Distribusi frekuensi responden berdasarkan robekan perineum pada kelompok perlakuan setelah dilakukan pijat perineum di Wilayah Kerja Puskesmas Jagir Surabaya 2017

\begin{tabular}{lcc}
\hline $\begin{array}{l}\text { Robekan } \\
\text { perineum }\end{array}$ & Frekuensi & Persentase $(\%)$ \\
\hline Tidak robek & 8 & 80 \\
\hline Robek tingkat 1 & 1 & 10 \\
\hline Robek tingkat 2 & 1 & 10 \\
\hline Robek tingkat 3 & 0 & 0 \\
\hline Robek tingkat 4 & 0 & 0 \\
\hline Jumlah & 10 & 100
\end{tabular}

Sumber : Data Primer, Juni 2017

Berdasarkan tabel 5.8 di dapatkan dari 10 responden menunjukkan hampir semuanya $(80 \%)$ tidak terjadi robekan perineum.

2) Kelompok kontrol

Karakteristik responden berdasarkan robekan perineum pada primigravida di Wilayah Kerja Puskesmas Jagir Surabaya dapat dilihat pada tabel sebagai berikut :

Tabel 5.9 Distribusi frekuensi responden berdasarkan robekan perineum pada kelompok kontrol di Wilayah Kerja Puskesmas Jagir Surabaya 2017

\begin{tabular}{lcr}
$\begin{array}{l}\text { Robekan } \\
\text { perineum }\end{array}$ & Frekuensi & $\begin{array}{c}\text { Persentase } \\
(\boldsymbol{\%})\end{array}$ \\
\hline Tidak robek & 0 & 0 \\
\hline Robek tingkat 1 & 4 & 40 \\
\hline Robek tingkat 2 & 6 & 60 \\
\hline Robek tingkat 3 & 0 & 0 \\
\hline Robek tingkat 4 & 0 & 0 \\
\hline Jumlah & 10 & 100 \\
\hline Sumber : Dat Pring
\end{tabular}

Sumber : Data Primer, Juni 2017

Berdasarkan tabel 5.9 di dapatkan dari 10 responden menunjukkan sebagian besar (60\%) terjadi robekan perineum. 
c. Pengaruh pijat perineum pada kehamilan trimester III terhadap robekan perineum primigravida di Wilayah Kerja Puskesmas Jagir Surabaya 2017

Tabel 5.10 Pengaruh pijat perineum pada kehamilan trimester III terhadap robekan perineum primigravida di Wilayah Kerja Puskesmas Jagir Surabaya 2017

\begin{tabular}{ccccc}
\multirow{2}{*}{$\begin{array}{c}\text { Pobekan } \\
\text { Perineum }\end{array}$} & \multicolumn{5}{c}{ Pijat perineum } \\
\cline { 2 - 5 } & $\begin{array}{c}\text { Perlakuan } \\
(\%)\end{array}$ & $(\mathrm{n})$ & $(\%)$ \\
\hline Tidak robek & 8 & 80,0 & 0 & 0,0 \\
\hline Tingkat I & 1 & 10 & 4 & 40 \\
\hline Tingkat II & 1 & 10 & 6 & 60 \\
\hline Tingkat III & 0 & 0 & 0 & 0 \\
\hline Tingkat IV & 0 & 0 & 0 & 0 \\
\hline Total & 10 & 100 & 10 & 100 \\
\hline Mann Whitney $\rho=0,001$ & & & \\
\hline Sumber
\end{tabular}

Sumber : Data Primer, Juni 2017

Berdasarkan tabel 5.10 menunjukkan dari 10 responden kelompok perlakuan hampir semuanya $(80 \%)$ tidak terjadi robekan perineum sedangkan pada 10 responden kelompok kontrol sebagian besar $(60 \%)$ terjadirobekan perineum.

Berdasarkan hasil uji statistic dengan menggunakan uji Mann Whitney program di komputer didapatkan nilai kemaknaan $\rho=0,001$ yang berarti Ho ditolak yang artinya ada pengaruh pijat perineum pada kehamilan Trimester III terhadap robekan perineum primigravida di Wilayah Kerja Puskesmas Jagir Surabaya.

\section{PEMBAHASAN}

1. Mengidentifikasi pijat perineum pada ibu primigravida.

Hasil yang didapat dari 10 responden data pijat perineum yang dilakukan pada kelompok perlakuan meliputi frekuensi pijat perineum menunjukkan setengahnya (50\%) melakukan 31$.40 \mathrm{kali}$ pemijatan perineum. Lama pijat perineum yang dilakukan responden menunjukkan hampir semuanya $(80 \%)$ melakukan pijat perineum selama $>5$ menit. Dan kedalaman pijat perineum yang dilakukan responden menunjukkan sebagian besar $(60 \%)$ melakukan pijat perineum $<2,54 \mathrm{~cm}$ di bawah mulut vagina. Pertama kali responden melakukan pijat perineum dengan di pijat oleh peneliti dan selanjutnya di lakukan oleh responden sendiri. Peneliti juga memantau dengan mendatangi rumah responden 1 minggu 3 kali untuk mengontrol ibu melakukan pijat perineum. Pada saat pertama peneliti memijat responden dengan mengajari pijat perineum antara lain frekuensi pemijatan, lama pemijatan, dan kedalaman pemijatan.

Responden pada kelompok perlakuan melakukan pemijatan dengan frekuensi yang berbeda-beda dikarnakan setiap responden melakukan pijat perineum di mulai tidak tepat pada usia kehamilan 36 minggu. Pada distribusi frekuensi usia kehamilan lama pemijatan yang dilakukan responden hampir semuanya melakukan pijat perineum selama $>5$ menit. Pemijatan yang dilakukan $>5$ menit karna responden memiliki waktu luang yang cukup untuk melakukan pijat perineum sehingga responden melakukan pijat sesuai dengan SOP. Sebagian kecil melakukan pijat selama $<5$ menit dikarnakan responden memiliki banyak kegiatan sehingga hanya bisa melakukan pemijatan $<5$ menit. Dan kedalaman pemijatan perineum $2,54 \mathrm{~cm}$, setiap responden melakukan pemijatan dengan kedalaman yang berbeda karena setiap responden juga memiliki ketebalan vagina yang tidak sama.

Semakin tebal vagina akan mempengaruhi kedalaman pada pemijatan perineum dan sebaliknya pada vagina yang tipis juga mempengaruhi kedalaman pada pemijatan perineum. Sesuai dengan teori menurut Yasie (2010) pada teknik pemijatan perineum yaitu taruh jari tidak lebih dari $2,54 \mathrm{~cm}$ di bawah mulut vagina (atau maksimum dua buku jari di bawah vagina). Waktu Pemijatan pada usia kehamilan 36 minggu atau dua minggu terakhir dan pemijatan dilakukan setiap hari menjelang hari $\mathrm{H}$ dengan durasi sebagai berikut: Minggu pertama 2 menit, sisa minggu menjelang persalinan 4-5 menit, dan berhenti pada saat ketuban pecah atau persalinan dimulai.

Berdasarkan penelitian ini pijat perineum dilakukan pada usia kehamilan trimester III atau 36 minggu, pada distribusi frekuensi usia kehamilan di dapatkan bahwa dari 10 responden pada kelompok perlakuan setengahnya (50\%) usia kehamilan <36 minggu dan >36 minggu. Pada tabel 5.4 di dapatkan bahwa dari 10 responden pada kelompok kontrol hampir selurunya $(70 \%)$ usia kehamilan >36 minggu. Pemijatan dapat dilakukan pada usia kehamilan 36 minggu atau 2 minggu sebelum persalinan, karna pemijatan pada usia tersebut dapat mepersiapkan responden dalam proses persalinan. Penelitian ini sejalan dengan penelitian Natami dkk (2013) bahwa pemijatan perineum dilakukan selama 2 minggu sebelum persalinan. Sesuai dengan teori menurut Indivara (2009), pijat perineum adalah teknik memijat perineum yang dilakukan saat hamil atau 2 minggu sebelum persalinan yang bermanfaat untuk melembutkan jaringan ikat, melancarkan peredaran darah, relaksasi. Tindakan ini akan mengurangi 
terjadinya ruptur perineum, episiotomi dan nyeri karena jahitan episiotomy

Populasi penelitian ini di bagi menjadi kelompok perlakuan dan kelompok kontrol, berdasarkan table 5.9 kelompok kontrol yang tidak dilakukan pijat perineum sebagian besar (60\%) terjadi robekan perineum. Kelompok kontrol yang tidak dilakukan pijat perineum tetap dilakukan asuhan sesuai standartnya, di pimpin cara mengejan yang benar saat persalinan dan juga dilakukan upaya untuk melenturkan perineum agar tidak terjadinya robekan perineum dengan mengikuti senam hamil. Pada kelompok perlakuan yang juga dilakukan asuhan sesuai standarnya, dipimpin cara mengejan yang benar saat persalinan, juga dilakukan upaya untuk mencegah terjadinya robekan perineum dengan mengikuti senam hamil dan dilakukan pijat perineum. Tetapi kejadian robekan perineum lebih tinggi pada kelompok kontrol dari pada kelompok perlakuan . Penjelasan diatas sesuai dengan penelitian Natami dkk (2013) perineum massage juga dapat sebagai mekanisme koping bagi ibu. Bagi ibu yang akan melahirkan rasa takut dan cemas saat persalinan akan berkurang karena selama hamil otot-otot disekitar perineum sudah dilakukan perineum massage sehingga jaringan disekitar menjadi elastis. Karakteristik ini sesuai teori menurut Yesie (2010), perineum terdiri dari kulit dan otot di antara vagina dan anus. Ketika kepala bayi menyembul di vagina, perineum dengan sendirinya meregang untuk memberi jalan keluar bayi. Pemijatan perineum yang dilakukan.

sejak bulan-bulan terakhir kehamilan menyiapkan jaringan kulit perineum lebih elastis sehingga lebih mudah meregang, meningkatkan elastisitas vagina untuk membuka, melatih ibu untuk aktif mengendurkan perineum ketika ia merasa tekanan saat kepala bayi muncul. Ini dapat mengurangi rasa sakit akibat peregangan. Pemijatan perineum mengurangi robekan perineum, mengurangi pemakaian episiotomi, dan mengurangi penggunaan alat bantu persalinan lainnya.

2. Mengidentifikasi robekan perineum pada ibu primigravida.

Dari hasil distribusi kelompok perlakuan menunjukkan hampir semuanya $(80 \%)$ tidak terjadi robekan perineum pada responden yang dilakukan pijat perineum. Pemijatan perineum baik dilakukan pada kehamilan trimester III. Pijat perineum memiliki berbagai manfaat untuk kelancaran proses persalinan salah satunya membantu mempersiapkan jaringan perineum sehingga membuat perineum menjadi elastis dan meminimalkan terjadinya robekan perineum. Pada pemijatan yang dilakukan di usia kehamilan trimester III oleh 10 responden diantaranya yang mengalami robekan hampir semuanya (80\%) tidak terjadi robekan perineum. Dan sebagian kecil $(10 \%)$ mengalami robekan tingkat 1 dan 2 hal ini dikarnakan responden tidak melakukan pijat perineum dengan rutin. Respoden yang tidak melaukan pijat dengan rutin dikarnakan bekerja sehingga tidak ada waktu untuk responden melakukan pijat perineum.

Penelitian ini juga sesuai dengan penelitian Natami dkk (2013) bahwa pemijatan perineum dilakukan selama 2 minggu sebelum persalinan sebanyak 6 kali dan dalam seminggu pertama dilakukan selama 3 menit dan minggu kedua selama 5 menit. Sesuai dengan teori pijat perineum menurut Indivara (2009) pijat perineum adalah teknik memijat perineum yang dilakukan saat hamil atau 2 minggu sebelum persalinan yang bermanfaat untuk melembutkan jaringan ikat, melancarkan peredaran darah, relaksasi. Tindakan ini akan mengurangi terjadinya ruptur perineum, episiotomi dan nyeri karena jahitan episiotomi.

Hasil distribusi kelompok kontrol menunjukkan hampir setengahnya $(60 \%)$ terjadi robekan perineum pada kelompok kontrol. Didapatkan dari 20 responden diantaranya 10 responden kelompok perlakuan dan 10 responden kelompok responden kelompok kontrol seluruhnya tidak terjadi robekan perineum pada kelompok perlakuan. Faktor yang mempengaruhi robekan meliputi faktor janin, faktor penolong, faktor maternal dan faktor umur ibu, pada penelitian ini dari faktor maternal primigravida, faktor janin berat bayi, dan faktor umur ibu. Penelitian ini sejalan dengan penelitian Natami dkk (2013), bahwa robekan perineum yang terjadi pada setiap responden dapat disebabkan oleh faktor-faktor yang mempengaruhi terjadinya robekan perineum. Sesuai teori menurut Oxorn \& Forte (2010), faktor penyebab terjadinya ruptur perineum terdiri atas faktor maternal, faktor janin, dan faktor penolong.

Faktor yang mempengaruhi robekan perineum antara lain faktor usia berdasarkan distribusi responden berdasarkan usia kelompok perlakuan seluruhnya (10\%) berusia 21-35 tahun kelompok perlakuan dan berdasarkan distribusi responden bedasarkan usia kelompok kontrol hampir selurunya (80\%) berusia 21-35 tahun kelompok kontro. Hal ini menunjukkan bahwa usia responden tersebut termasuk kategori usia produktif sehingga fungsi reproduksinya berkembang dengan sempurna. Dan katagori responden yaitu primigravida yang mana jalan lahir belum pernah dilalui dan perineum belum elastis maka dari itu kejadian robekan pada primigravida lebih tinggi. Penelitian ini sejalan dengan penelitian Liu, 2008 dalam (Natami, 2013) 
menyatakan bahwa $85 \%$ kelahiran pertama selalu disertai robekan perineum. Hubungan robekan perineum dengan paritas adalah kerusakan jaringan lunak. Kerusakan jaringan jalan lahir biasanya lebih nyata pada wanita primigravida karena jaringan pada primigravida lebih padat dan lebih resisten dari pada wanita multigravida. Seperti teori menurut Depkes RI (2009), umur ibu juga dapat menjadi faktor penyebab ruptur perineum. Pada usia di bawah 20 tahun, fungsi reproduksi seorang wanita belum berkembang dengan sempurna. Sedangkan pada usia di atas 35 tahun fungsi reproduksi seorang wanita sudah mengalami penurunan dibanding fungsi reproduksi normal sehingga kemungkinan untuk terjadinya komplikasi pasca persalinan terutama perdarahan seperti ruptur perineum akan lebih besar.

Selain usia, berat bayi juga merupakan faktor terjadinya robekan hal ini berdasarkan hasil distribusi responden berdasarkan besar bayi bahwa 10 responden kelompok perlakuan setengahnya (50\%) besar bayi 3100-3500 gram. Dan berdasarkan distribusi responden berdasarkan besar bayi bahwa 10 responden kelompok kontrol hampir setengahnya (40\%) besar bayi 3100-3500 dan 3600-4000 gram. Besar bayi mempengaruhi terjadinya robekan perineum, berat bayi normal 2500-3500 gram. Jika berat bayi lebih dari 3500 gram maka bayi tersebut tergolong bayi besar. Penelitian ini juga sesuai penelitian Natami (2013), faktor bayi yang akan mempengaruhi terjadinya robekan perineum. berat bayi normal sekitar 2500-3500 gram. Jika berat bayi lebih dari 3500 gram disebut bayi besar atau makrosomia.

Penelitian ini juga sesuai penelitian Natami (2013), faktor bayi yang akan mempengaruhi terjadinya robekan perineum. berat bayi normal sekitar 2500-3500 gram. Jika berat bayi lebih dari 3500 gram disebut bayi besar atau makrosomia. Makrosomia disertai dengan meningkatnya resiko trauma persalinan melalui vagina seperti distorsia bahu, kerusakan fleksusbrakialis, patah tulang klavikula dan kerusakan jaringan lunak pada ibu seperti laserasi jalan lahir dan robekan pada perineum. semakin besar bayi yang dilahirkan dapat meningkatkan risiko terjadinya rebekan perineum. Seperti teori menurut Saifuddin (2002), semakin besar berat badan bayi yang dilahirkan akan meningkatkan risko terjadinya ruptur perineum karena perineum tidak cukup kuat menahan regangan kepala bayi dengan berat badan bayi yang benar, sehingga pada proses kelahiran bayi dengan berat badan bayi lahir yang sering terjadi ruptur.
3. Pengaruh pijat perineum pada kehamilan trimester III terhadap robekan perineum primigravida di Wilayah Kerja Puskesmas Jagir Surabaya

Berdasarkan hasil uji pengaruh menunjukkan dari 10 responden kelompok perlakuan yang tidak terjadi robekan perineum hampir semuanya $(80 \%)$, dan dari 10 responden kelompok kontrol sebagian besar (60\%) terjadi robekan perineum.

Hasil penelitian di Wilayah Kerja Puskesmas Jagir Surabaya setelah di analisis dengan uji statistik Mann Whitney program di komputer didapatkan nilai kemaknaan $\rho=0,001$ yang berarti Ho ditolak yang artinya ada pengaruh pijat perineum pada kehamilan Trimester III terhadap robekan perineum primigravida di Wilayah Kerja Puskesmas Jagir Surabaya. Dapat dikatakan bahwa pijat perineum bisa membuat perineum menjadi lentur sehingga tidak terjadi robekan perineum pada ibu primigravida. Pemijatan yang dilakukan secara rutin sebelum persalinan membantu ibu dalam proses persalinan yang lancar dan nyaman. Penelitian ini serupa dengan hasil penelitian yang dilakukan Natami dkk (2013) yaitu tentang "Pengaruh Perineum Massage Terhadap Derajat Robekan Perineum Pada Ibu Primigravida Di BPS Widjayati Dan BPS Desak Kecamatan Negara" bahwa responden yang dilakukan responden yang dilakukan pijat perineum enam orang $(60 \%)$ tidak terjadi robekan perineum sedang responden yang tidak dilakukan pijat perineum hamper semuanya (70\%) terjadi robekan perineum. Karakteristik ini sesuai teori menurut Marie (2007), pijat perineum adalah salah satu cara paling kuno dan paling pasti untuk meningkatkan kesehatan, aliran darah, elestisitas, dan relaksasi otot-otot dasar panggul. Teknik ini jika dilatih pada tahap akhir kehamilan, sekitar enam sampai delapan minggu sebelum persalinan, juga akan membantu mengenali dan membiasakan diri dengan jaringan yang dilalui oleh bayi.

satu cara paling kuno dan paling pasti untuk meningkatkan kesehatan, aliran darah, elestisitas, dan relaksasi otot-otot dasar panggul. Teknik ini jika dilatih pada tahap akhir kehamilan, sekitar enam sampai delapan minggu sebelum persalinan, juga akan membantu mengenali dan membiasakan diri dengan jaringan yang dilalui oleh bayi.

\section{KESIMPULAN}

Dari hasil analisis dan pembahasan yang telah dilakukan oleh peneliti maka dapat disimpulkan bahwa: Pijat perineum yang dilakukan pada ibu primigravida meliputi frekuensi pijat perineum menunjukkan setengahnya melakukan 31-.40 kali 
pemijatan perineum, lama pijat perineum menunjukkan hampir semuanya melakukan pijat perineum selama $>5$ menit, dan kedalaman pijat perineum menunjukkan sebagian besar melakukan pijat perineum $<2,54 \mathrm{~cm}$ di bawah mulut vagina. Ibu primigravida yang mengalami robekan perineum setelah dilakukan pijat perineum hampir semuanya tidak terjadi robekan perineum, dan yang tidak dilakukan pijat perineum sebagian besar mengalami robekan perineum. Ada pengaruh pijat perineum terhadap robekan peineum pada primigravida.

\section{DAFTAR PUSTAKA}

Aprillia, Yasie. 2010. Hipnostetri: Rileks, Nyaman, dan Aman Saat Hamil \& Melahirkan. Jakarta: Gagas Media.

Batbual, Bringiwatty. 2010. Hypnosis Hypnobrthing Nyeri Persalinan Dan Berbagai Metode Penanganan. Gosyeng Publishing; Yogyakarta.

EGC.

Benson, P \& Pernoll. (2009). Buku saku Obsetry Gynecology William. Jakarta

Danuatmaja, Bonny \& Meiliasari, Mila. 2008. Persalinan Normal Tanpa Rasa Sakit. Jakarta: Puspa Sehat.

Derek Llewellyn dan Jones. 2007. Obstetri dan Ginekologi., Jakarta : EGC

Depkes RI. 2009. Usia Kehamilan. Jakarta : Depkes RI.

Dwienda, Octa R, dkk. 2015. Cara Mudah Menjadi Bidan yang Komunikatif. Yogyakarta: Deepublish.

Fatimawati, S \& Purwaningsih, W. 2010. Asuhan Keperawatan Maternitas. Nuha Medika; Yogyakarta.

Indivara. 2009. Panduan senam hamil. Jakarta : Rineka Cipta

JNPK-KR. 2007. Pelatihan asuhan persalinan normal buku acuan. Jakarta: Jaringan Nasional Pelatihan Klinik Kesehatan reproduksi

Manuaba, dkk. 2007. Pengantar Kuliah Obstetri. Jakarta: EGC.

Marie F. 2007. Hypnobirthing The Mogan Method Metode Melahirkan Secara Aman, Mudah, dan Nyaman. Jakarta: PT Bhana Ilmu Populer.
Maryunani, A \& Puspita E. 2013. Asuhan Kegawatdaruratan Maternal \& Neonatal. Jakarta: TIM.

Molika, Ewa. 2015. 275 Tanya Jawab Seputar Kehamilan \& Melahirkan. Jakarta: Vicosta Publising.

Natami, P.A, Runiari N, Putri M. 2013. Pengaruh Massage Terhadao Derajat Robekan Perineum Pada Ibu Primigravida Di BPS Widjayati Dan BPS Desak Kecamatan Negara. www.googlescholar.com (diakses pada tangal 4 juli 2017 pukul 09.WIB)

Nugroho, Taufan. 2012. Obsgyn Obstetri dan Ginekologi untuk Kebidanan dan Keperawatan. Yogyakarta: Nuha Medika.

Nugroho, Taufan. 2012. Patologi Kebidanan. Yogyakarta: Nuha Medika

Oxorn, Harry. \& Forte, William R. 2010. Ilmu Kebidanan Patologi dan Fisiologi Persalinan. Yogyakarta: C.V Andi.

Putra, Sitiatava R. 2016. Cara Mudah Melahirkan dengan Hypnobirthing. Yogyakarta: Laksana.

Putrono \& Wagiyo. 2016. Asuhan Keperawatan Maternitas Antenatal, Intranatal Bayi Baru Lahir \& Fisiologi Patologis. Yogyakarta: Andi Offset.

Prawirohardjo, wiknjosastro. 2005. Ilmu Kebidanan. Yogyakarta : Yayasan Bina Pustaka.

Setyorini, Retno H. 2013. Bempelajaran Tentang Persalinan. Yogyakarta: Graha Ilmu.

Sinsi, Iis. 2006. Seri Kesehatan Ibu dan Anak Masa Kehamilan dan Persalinan. Jakarta: Elex Media Komputindo.

Widajaka, W \& Ana Wardatul J. 2012. Enjoy Your Pregnancy, Moms. Jakarta: AgroMedika Pustaka. 